\section{Pulmonary artery pressures with tension pneumothorax}

Five hours following an uneventful coronary artery bypass graft operation, an otherwise healthy 54-yr-old man developed a pneumothorax while his lungs were being ventilated in the recovery room. Neither arterial blood gas analysis, ventilatory variables, nor clinical examination had suggested this diagnosis, which was made subsequent to a chest radiograph taken as part of the assessment of hypotension. At the same time, the waveform of the pressure tracing from his pulmonary artery catheter changed inexplicably while attempting balloon inflation as part of the assessment of the hypotensive episode. In retrospect, the changes in the pressure tracing most likely were due to alterations in the pulmonary vasculature associated with the pneumothorax. These changes can be explained in terms of a well-known physiological model. If such changes are encountered in similar circumstances, a tension pneumothorax should be suspected.

Un homme de 54 ans, sous ventilation mécanique, développa un pneumothorax cinq heures après une revascularisation coronarienne. Le diagnostic que ni les gaz artériels, ni les variables respiratoires, ni l' examen clinique n'avaient laissé suspecter fut établi à l'aide d'une radiographie pulmonaire faite lors d' un épisode d'hypotension. Le tracé des pressions transmises par le cathéter de l'artère pulmonaire se comportait alors de façon inhabituelle lorsqu' on en gonflait le ballon, à la recherche de la cause de cette hypotension. En rétrospective, ce tracé particulier était probablement relié aux effets du pneumothorax sur les vaisseaux pulmonaires que l'on peut d'ailleurs expliquer à partir d'un modèle physiologique connu. Il faut donc être à l'affât d' un pneumothorax si l'on rencontre un tracé semblable en des circonstances similaires.

\section{Key words}

COMPLICATIONS: pneumothorax;

MEASUREMENT TECHNIQUES: pulmonary artery.

From the Department of Anesthesiology, Vancouver General Hospital, Vancouver, B.C.

Address correspondence to: Dr. L.W. Lee, Department of Anesthesiology, Vancouver General Hospital, 855 W 12 Avenue, Vancouver, B.C. V5Z IM9.
In managing hypotension following cardiac surgery, the assessment of preload and cardiac output using a balloontipped flow-directed pulmonary artery (PA) catheter supplies useful information that otherwise is not available. With the balloon inflated and the catheter in the wedged position, the resulting pulmonary artery wedge pressure (PWP) estimates the left atrial pressure (LAP). The factors that influence this relationship have recently been reviewed, ${ }^{1,2}$ and include heart rate, rhythm, pulmonary vascular resistance, mitral valve disease, left ventricular compliance, hypovolaemia and alveolar pressure. This case documents a change in the PA pressure which appears to have resulted from increased intrathoracic pressure due to a tension pneumothorax which occurred in a ventilated patient without clinically significant preexisting lung disease.

\section{Case report}

A 54-yr-old $95 \mathrm{~kg}$ man with a history of remote myocardial infarction, angina, and smoking, underwent coronary artery bypass surgery including a left internal mammary artery graft to the anterior descending artery. The anaesthetic agents were sufentanil, fentanyl, morphine and pancuronium. The procedure was uneventful. He was weaned easily from cardiopulmonary bypass, and was transferred to the recovery room with infusions of dopamine $2 \mu \mathrm{g} \cdot \mathrm{kg}^{-1} \cdot \mathrm{min}^{-1}$ and nitroglycerine (NTG) $0.5 \mu \mathrm{g} \cdot \mathrm{kg}^{-1} \cdot \mathrm{min}^{-1}$ running. After induction of anaesthesia, a balloon-tipped flow-directed catheter (Opticath Fiberoptic Pulmonary Artery Catheter P7 1 10-EH, Abbott Laboratories, North Chicago, IL, size 7 French) was inserted into the PA via the right internal jugular vein for continuous pressure monitoring (Series 7000 Monitor, Marquette Electronics Inc., Milwaukee, WI). The PA diastolic pressure (PAD) and the PWP were 11 and 7 $\mathrm{mmHg}$ respectively. On weaning from bypass, PAD was $15 \mathrm{mmHg}$.

In the recovery room, the initial blood pressure (BP) was $140 / 80 \mathrm{mmHg}$ and the PAD was $19 \mathrm{mmHg}$. The configuration of the PA pressure waveform appeared normal, both in the unwedged and wedged positions. A chest radiograph confirmed proper placement of the tip of the PA catheter in the proximal right PA, correct tracheal tube position, and full inflation of both lungs. Ventilator 


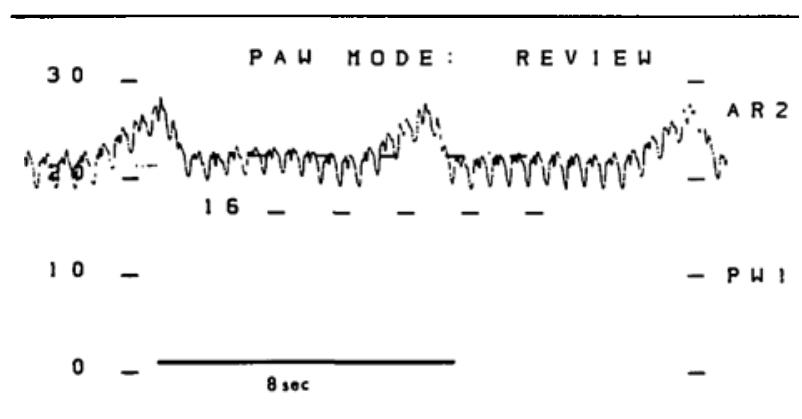

FIGURE 1 Vertical axis is pressure in $\mathrm{mmHg}$; horizontal axis is time, with the whole strip representing approximately $30 \mathrm{sec}$. This shows the PA pressure waveform with the PA catheter at $37 \mathrm{~cm}$ and balloon partially inflated in the presence of a tension pneumothorax. Note the apparent elevation in diastolic pressure, without an increase in the systolic pressure, compared with Figure 2.

settings (Bennett MA2+2, Puritan-Bennett Corporation) in SIMV mode were: tidal volume of $1200 \mathrm{ml}$, rate of eight breaths per minute, PEEP of $5 \mathrm{~cm} \mathrm{H}_{2} \mathrm{O}$, and $\mathrm{FIO}_{2}$ of 0.6 . The peak inspiratory pressure (PIP) was $30 \mathrm{~cm} \mathrm{H}_{2} \mathrm{O}$, and arterial blood gas (ABG) analysis showed: $\mathrm{pH} 7.42$, $\mathrm{PCO}_{2} 40 \mathrm{mmHg}, \mathrm{HCO}_{3} 26 \mathrm{mEq} \cdot \mathrm{L}^{-1}, \mathrm{PO}_{2} 248 \mathrm{mmHg}$. The mixed venous oxygen saturation $\left(\mathrm{Sv}_{2}\right)$ from the $\mathrm{PA}$ catheter was 65 per cent. These are representative of the usual findings in stable patients immediately after surgery in our cardiac surgical population.

Five hours later, the BP was $105 / 50 \mathrm{mmHg}$ with a PAD of $15 \mathrm{mmHg}$ and $\mathrm{S}_{\overline{\mathrm{V}}} \mathrm{O}_{2}$ of 60 per cent. ABG analysis was unchanged except for $\mathrm{PO}_{2} 110 \mathrm{mmHg}$ at $\mathrm{FIO}_{2} 0.4$. Breath sounds were equal bilaterally, the trachea was in the midline, and the PIP was unchanged. The NTG infusion rate was decreased and plasma was given. After increasing transiently to $120 / 70 \mathrm{mmHg}$, the BP decreased to $90 / 50 \mathrm{mmHg}$ and the $\mathrm{S}_{\bar{v}} \mathrm{O}_{2}$ to 55 per cent. Repeat $\mathrm{ABG}$ analysis was unchanged except for $\mathrm{PO}_{2} 88 \mathrm{mmHg}$ at $\mathrm{FIO}_{2}$ 0.35 . The waveform of the PA pressure tracing became flattened, similar to a wedged position tracing, but resumed a normal configuration and a pressure of $21 / 12$ $\mathrm{mmHg}$ on withdrawing the PA catheter from 40 to $37 \mathrm{~cm}$. Slow inflation of the balloon of the PA catheter unexpectedly resulted in a fluctuating waveform with a mean pressure of $22 \mathrm{mmHg}$ (Figure 1) before the balloon was fully inflated. The balloon was immediately deflated and the waveform reverted to its normal unwedged appearance.

A chest radiograph five minutes later revealed a 40 per cent right pneumothorax with no mediastinal shift. The PA catheter was in the proximal right PA. Insertion of a chest tube into the right thorax resulted in a gush of air following which the BP increased to $160 / 100 \mathrm{mmHg}$ and the $\mathrm{Sin}_{2}$ to 73 per cent. The PAP was $22 / 14 \mathrm{mmHg}$ (Figure 2, left) and the PWP was $10 \mathrm{mmHg}$ (Figure 2,

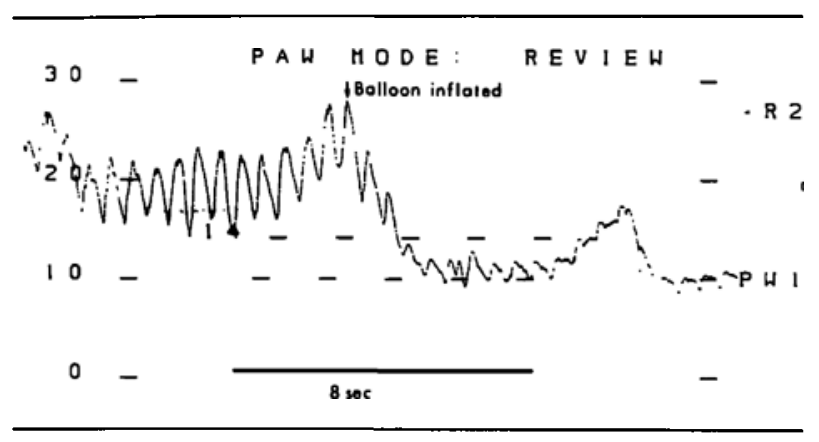

FIGURE 2 PA pressure waveform with PA catheter at $37 \mathrm{~cm}$ after the pncumothorax has been decompressed. The left half shows the PA pressure in the non-wedged position. The balloon is inflated near the midpoint of the strip and the right half shows the PA pressure in the wedged position.

right). $\mathrm{ABG}$ analysis was unchanged except for $\mathrm{PO}_{2} 125$ $\mathrm{mmHg}$ at $\mathrm{FIO}_{2}$ 0.45. Reexpansion of the right lung was confirmed radiologically. There were no further problems.

\section{Discussion}

At our institution, it is not unusual for the BP, PAD and $\mathrm{S}_{\mathrm{V}} \mathrm{O}_{2}$ to decrease slightly three to six hours after open heart surgery due to rewarming of the patient and concomitant vasodilatation. Thus, having assessed the ventilation and gas exchange to exclude a pneumothorax as is normal practice, the initial management of the decreasing BP was to reduce the vasodilator dose and support the intravascular volume. The PA catheter appeared to advance spontaneously into the wedged position without the balloon being inflated, an event which occurs not uncommonly when intravascular volume is decreasing. This is attributed to the pulmonary artery being less distended at lower PA pressures, and to decreased heart distension due to diminished preload. Thus, the PA catheter which is fixed at the point of percutaneous entry protrudes more distally into a PA of smaller diameter. Treatment is to withdraw PA catheter a few centimeters and this was done. However, after a transient response, the hypotensive trend continued. A chest $x$-ray was ordered and an attempt was made to assess the PWP and cardiac output, and this resulted in the aberrant pressure wave tracing. The balloon was deflated and the PA catheter not wedged until its position could be assessed on the radiograph.

The diagnosis of a pneumothorax was unexpected, although it is always considered in this clinical setting. The PIP and expired volume had not changed, and while the $\mathrm{PO}_{2}$ was lower, this was mainly attributed to decreasing the $\mathrm{FIO}_{2}$ since there had been no change in the calculated alveolar/arterial $\mathrm{PO}_{2}$ difference $\left(\mathrm{A}-\mathrm{aDO} \mathrm{O}_{2}\right)$. Of particular note, the physical examination of the chest was normal. The static compliance was not measured 
during this episode. There was probably a tension component to the pneumothorax because the haemodynamic compromise was completely reversed after insertion of the chest tube and the release of gas.

Examination of the printout of the PA pressure tracing showed that the diastolic pressure was elevated, while the systolic pressure remained unchanged. McLoud ${ }^{3}$ described two cases in which ventilated patients with ARDS developed similar changes due to tension pneumothoraces. The changes were hypothesized to have been due to pulmonary vasoconstriction which decreased the size of the vascular bed relative to the circulating volume. This does not explain why the PA diastolic but not the PA systolic pressure was increased.

An analysis based on the principles described by West ${ }^{4}$ can explain this phenomenon. West defined three lung zones based on the alveolar pressure $\left(P_{A}\right)$, pulmonary arterial pressure $\left(P_{\mathrm{a}}\right)$, and pulmonary venous pressure $\left(P_{v}\right)$, and their changing relationships due to the force of gravity acting on the column of pulmonary blood at different vertical levels in the lung. Zone $1\left(P_{A}>P_{a}>P_{v}\right)$ does not occur normally but can occur in situations of decreased $P_{a}$ with greatest likelihood at the top of the lung. There is no pulmonary blood flow in zone 1 so it will be ignored. In zone $3\left(P_{a}>P_{v}>P_{A}\right)$, which comprises the more dependent parts of the lung, pulmonary blood flow is determined by the arterial-venous pressure gradient. Pulmonary blood flow occurs as long as $\mathbf{P}_{\mathbf{A}}$ does not exceed $\mathrm{P}_{\mathrm{a}}$ and gives rise to the pulmonary arterial pressure waveform measured by PA catheter. Usually, the pulmonary blood flow directs the PA catheter preferentially into this zone when the balloon is inflated. Between zones 1 and 3 is an intermediate zone $2\left(P_{a}>P_{A}>P_{v}\right)$ where pulmonary blood flow is determined by the gradient between $P_{a}$ and $P_{A}$. Zone 3 can be converted to zones 2 or 1 either by a decrease in $P_{v}$ or $P_{a}$ respectively to below $P_{A}$, or by an increase of $P_{A}$ to greater than $P_{v}$ or $P_{a}$ respectively. During a positive pressure inspiration which causes $P_{A}$ to exceed $P_{v}$, pulmonary blood flow should vary with the gradient between $P_{a}$ and $P_{A}$.

In this patient, and probably in the two described by McLoud, ${ }^{3}$ the tension pneumothorax caused an increase in pleural pressure $\left(\mathrm{P}_{\mathrm{Pl}}\right)$ which was transmitted to the pulmonary vasculature to act like the $\mathrm{P}_{\mathrm{A}}$ in West's model. This could have the effect of converting the position of the $\mathrm{PA}$ catheter from zone 3 to zone 2 . If $\mathrm{P}_{\mathrm{Pl}}$ increases to exceed PAD, blood flow during diastole ceases and the PA catheter diastolic pressure tracing reflects the $P_{P I}$ rather than the pressure in the pulmonary artery. During systole, it continues to reflect pulmonary artery pressure. In this case, the PA catheter pressure tracing showed this change only with balloon inflation, probably because the
PA catheter had been pulled back to a position in a large proximal branch of the right PA, and only when advanced with balloon inflation was it in a vessel distal enough to be fully affected by the $P_{P 1}$.

This case illustrates several important features. A tension pneumothorax causing haemodynamic compromise need not be accompanied by hypoxaemia, physical findings or changes in ventilatory variables. Perhaps static compliances, which were not measured, would be a more sensitive parameter to identify changes in ventilatory mechanics, but this would not be without risk in this patient population. When the PA diastolic pressure increases without an increase in the PA systolic pressure, and there is a predisposition to tension pneumothorax, then this may indicate a tension pneumothorax.

\section{References}

1 Nadeau S, Noble WH. Misinterpretation of pressure measurements from the pulmonary artery catheter. Can Anaesth Soc J 1986; 33: 352-63.

2 King EG. Influence of mechanical ventilation and pulmonary disease on pulmonary artery pressure monitoring. Can Med Assoc J 1979; 121: 901-4.

3 McLoud TC, Barash PG, Ravin CE, Mandel SD. Elevation of pulmonary artery pressure as a sign of pulmonary barotrauma (pneumothorax). Crit Care Medicine 1978; 6 : 81-4.

4 West JB. Respiratory Physiology - the Essentials. 2nd ed. Baltimore: Williams and Wilkins, 1979; 32-50. 